\title{
PARAMENTAÇÃO CIRÚRGICA: AVALIAÇÃO DE SUA ADEQUAÇÃO PARA A PREVENÇÃO DE RISCOS BIOLÓGICOS EM CIRURGIAS - PARTE II: OS COMPONENTES DA PARAMENTAÇÃO*
}

\author{
SURGICAL SCRUB: EVALUATING ITS ADEQUATION FOR PREVENTING \\ BIOLOGICAL RISKS IN SURGERIES. PART II: \\ THE COMPONENTS OF THE SURGICAL SCRUB
}

\author{
Cibele Estanislau da C. Monteiro ** \\ Rúbia Aparecida Lacerda *** \\ Marielen Silva de Oliveira Paz ** \\ Viviane Peres da Conceição **
}

MONTEIRO, C. E.da C. et al. Paramentação Cirúrgica: avaliação de sua adequação para a prevenção de riscos biológicos em cirurgias. Parte II: os componentes da paramentação. Rev.Esc.Enf.USP, v. 34, n. 2, p. 185-95, jun. 2000.

\section{RESUMO}

O estudo elaborou critérios de avaliação dos componentes da paramentação cirúrgica de hospitais do município de São Paulo. A maior dificuldade nessa elaboração deveu-se à inexistência de normas e consenso sobre a porosidade dos tecidos como barreira microbiológica e de contato com sangue e outros fluidos. Contudo, foi possivel reconhecer aspectos positivos e problemáticos. Observou-se que existe semelhanças dos componentes entre os hospitais, no que se refere a modelo e tipo de tecido. As luvas foram os componentes com maior indice de adequação e os propés, os de maior indice de inadequação. $O$ aspecto mais problemático referiu-se aos controles de aquisição e de reprocessamento dos componentes re-utilizáveis.

PALAVRAS-CHAVE: Infecção hospitalar. Roupa de proteção.

\begin{abstract}
The study elaborated evaluation patterns of the components of the surgical scrub in hospitals of the district of São Paulo. The most important difficulty was the lack of rules and consent on the types of the fabrics, as a microbiological and contact with blood and other fluids barrier. However, it was possible to identify positive and problematic aspects. It was observed that the components are similar among the hospitals, considering the design and the way of fabrics production. Gloves were the ones with the best quality results, while shootweares were the worst. The most problematic aspect was referred to the acquisition controls and the re-use process of the components
\end{abstract}

KEYWORDS: Cross infection. Protective clothing.

\section{INTRODUÇÃO}

A parte I deste estudo pesquisou a adequação do uso da paramentação cirúrgica em hospitais do município de São Paulo. A parte II, aqui apresentada, pesquisou a adequação das especificações técnicas dos componentes da paramentação nos mesmos hospitais, tendo como objetivos: a) reconhecer,através de literatura científica, normas e legislações, as considerações mais recentes sobre os componentes da paramentação cirúrgica e sua adequação para o controle de riscos biológicos, no que se refere ao tipo de tecido, variação de tamanho e modelo (design); b) elaborar um instrumento de

\footnotetext{
* Pesquisa realizada com apoio do Programa Institucional de Bolsas de Iniciação Científica do CNPq (PIBIC

** CNPq). Enfermeiras. Graduadas pela Escola de Enfermagem da USP.

*** Enfermeira. Professora Doutora da Escola de Enfermagem da USP.
} 
avaliação dos componentes da paramentação cirúrgica, a partir das considerações obtidas; c) avaliar os componentes da paramentação cirúrgica utilizados em hospitais do municipio de São Paulo, de acordo com os critérios de avaliação elaborados.

\section{METODOLOGIA}

Tratou-se de uma pesquisa exploratória e descritiva, com investigação pautada em entrevista e análise dos componentes da paramentação cirúrgica. A população foi composta por enfermeiros de centro cirúrgico e de centro de material de 14 hospitais do Município de São Paulo, sendo 4 privados e 10 públicos, 8 de médio porte e 6 de grande .porte.

$\mathrm{O}$ instrumento utilizado na coleta de dados constou de 2 partes (anexo 1):

1- Parte A: Levantamento de informações sobre os hospitais

2- Parte B: Análise visual dos componentes da paramentação e entrevista com enfermeiros do centro cirúrgico e/ou centro de material, para reconhecer os tipos de controle de reprocessamento.

Para a avaliação dos componentes da paramentação foi construído um instrumento contendo critérios previamente elaborados (Anexo 2), a partir do referencial teórico apresentado no item a seguir.

\section{CONSIDERAÇÕES TEÓRICAS PARA UMA AVALIAÇÃO DOS COMPONENTES DA PARAMENTAÇÃO CIRÚRGICA}

Uma discussão sobre especificações técnicas da paramentação, deve considerar: a) tipo de tecido; b) modelo (design); c) tamanho. Tais considerações serão discutidas a seguir:

\section{1) Avental e uniforme privativo}

Em nosso meio, a maioria dos uniformes privativos, aventais e campos cirúrgicos são de tecido de algodão reprocessável. Algumas tentativas de padronização de sua confecção, no que se refere a barreira para líquidos e penetração de microrganismos, vêm sendo efetuadas e são citadas por RODRIGUES ${ }^{23}$. Contudo, ainda não se conseguiu determinar o número máximo permitido de reprocessamentos, sob dadas condições, que não altere sua composição original. Tal situação vem propiciando de um lado, uma larga variedade na sua seleção e por outro, justificando o uso crescente de tecidos alternativos, geralmente denominados de não-tecido.

Por referência aos aventais, os de não - tecidos podem ser totalmente impermeáveis ou com resistência a líquidos sob determinadas condições. Também pode ser encontrada uma composição mista, com reforço na parte da frente e nos antebraços, podendo ser de filmes ou membranas impermeáveis e camadas duplas do mesmo material. A maioria são descartáveis ${ }^{20}$. Contudo, também não existem ainda normas sobre suas especificações técnicas, ficando dependentes daquelas apresentadas pelos fabricantes. Além disso, a crescente utilização de descartáveis vem provocando polêmica sobre o aumento do lixo de materiais não degradáveis ou que exigem longo tempo para sua degradação.

A OSHA (Occupational Safety and Health Administration) dos E.U.A considera apropriadas, roupas que não permitem a passagem de sangue e outros materiais potencialmente contaminados, sob condições normais de uso e durante toda a duração do procedimento.

Descartáveis ou não, de tecido ou impermeáveis, ainda não se chegou a um consenso que estabeleça a sua porosidade ideal. Geralmente, a sua seleção é feita após limitada pesquisa com os próprios usuários da S.O., que consideram antes o conforto do que a sua performance como barreira microbiológica e proteção efetiva do corpo ao sangue e outros fluidos orgânicos.

Os testes laboratoriais dos fabricantes, ainda que confiáveis, não são considerados efetivos por não conseguirem reproduzir com fidelidade os movimentos e os desgastes ocorridos na prática. Mesmo os de plástico reforçado e aqueles reutilizáveis que se comportam bem nos testes de laboratório podem falhar conforme o esforço realizado durante um procedimento de longa duração9.

Ao se optar por tecidos com porosidade menor do que o tamanho das bactérias, há que se questionar o seu grau de conforto. Particularmente em cirurgias prolongadas, os aventais ao mesmo tempo aumentam a transpiração e inibem sua evaporação. O excesso de transpiração pode aumentar a liberação da flora do usuário ao ambiente $\mathrm{e}$, conseqüentemente, aumentar o risco de infecção do sítio cirúrgico. Tentativas de se estabelecer exaustão dessa transpiração através de sistemas de ventilação dentro da paramentação, citada em alguns estudos, devem ser consideradas "mirabolantes", principalmente em alguns centro cirúrgicos, onde ainda se "luta" para pelo menos se utilizar corretamente a paramentação completa com os materiais disponiveis.

Para AYLIFFE et $\mathrm{al}^{3}$, as roupas convencionais dos uniformes privativos oferecem alguma proteção dos trabalhadores contra contaminação por contato (se estiverem secas), mas não reduzem a contaminação do ar ambiente com bactérias oriundas da pele dos usuários. As bactérias escapam através dos poros do tecido e pelas. aberturas das calças nos 
tornozelos, porém, há pouca liberação pelas aberturas no pescoço, mangas e cintura. Um tecido com porosidade de 7 a 10 micras e o fechamento das calças nos tornozelos podem reduzir a dispersão de bactérias.

No entanto, desconhecemos estudos que constatem sob que condições as bactérias conseguem passar pelas tramas dos tecidos convencionais. Se isso ocorreria passivamente, ou apenas sob forte movimentação, transpiração, pressão, etc. Seriam necessárias pesquisas in loco, com metodologias rigorosas, que permitissem verificar a contaminação microbiana desses tecidos utilizados pela equipe cirúrgica antes, durante e após as cirurgias.

Pesquisa com testes com sangue sintético mostrou que os aventais regulares ou convencionais e os reforçados com camada dupla do mesmo tecido ofereceram diferentes graus de resistência a líquidos. Os primeiros mostraram alguma resistência a respingos e encharcamento de liquidos na superficie. Já, aventais reforçados com filmes ou membranas impermeáveis são geralmente à prova de líquidos, significando que eles resistem à penetração visivel de sangue sob pressão. Alguns desses aventais também são resistentes à penetração de vírus 20

Por outro lado e, com relação aos riscos ocupacionais, vários estudos epidemiológicos mostram freqüência de contato ocupacional com sangue bem menor na parte do corpo protegida com avental e uniforme privativo quando comparada com mãos e rosto, além de não ter sido observado casos de transmissão de infecção por contato cutâneo 18,19 Sendo assim, há que se perguntar sobre a real necessidade de uso generalizado de vestimentas totalmente impermeáveis. Além disso, as injúrias percutâneas têm ocorrido predominantemente com agulhas e outros objetos cortantes nos dedos e mãos enluvados 4,14,18, merecendo questionar se mesmo esses componentes impermeáveis são suficientes para impedir esse tipo de ferimento na parte do corpo que eles protegem. TELFORD; QUEBBEMAN ${ }^{25}$ concluem que não existem evidências sobre a melhor proteção entre aventais descartáveis e não descartáveis.

Parece mais viável que a seleção de aventais e uniformes privativos, além de apresentar um padrão mínimo de barreira contra passagem de microrganismos e contato com sangue e outros fluidos, também deva considerar os diferentes fatores relacionados à amplitude dos riscos de exposição ao sangue e outros modos de transmissão para cada membro da equipe e para cada tipo de procedimento. Requisitos adicionais de proteção pelo avental vão depender de cirurgias prolongadas, com grande quantidade de perda sanguínea ou outros fluidos, de emergência, de grande extensão e profundidade, etc.

Em situações cotidianas e, devido não existirem ainda resultados de pesquisas comparativas e com metodologias rigorosas quanto à porosidade, consideraremos adequado tanto componentes impermeáveis, quanto de tecido de algodão reprocessável, desde que existam controles na sua aquisição e no seu reprocessamento.

Esses controles referem-se a: 1) avaliação da porosidade das fibras; b) testes de resistência em diferentes circunstâncias; c) controle do reprocessamento (porcentagem de encolhimento, número de reprocessamentos, processos aplicados, como temperatura e umidade da lavagem e esterilização, acato de um período para descanso das fibras e o desgaste do tecido; d) avaliação da integridade (presença de furos, rasgos, descontinuidade da costura, cerzimento, tiras de amarração, etc.); e) limpeza após lavagem (presença de ingredientes tóxicos, manchas, etc.) 1,15.

Além da polêmica sobre a melhor constituição dos tecidos, há que se questionar também se os modelos e os tamanhos propiciam a cobertura e a barreira a que se propõem.

O avental cirúrgico deve possuir OPAS e amarraduras, permitindo cobertura completa do tronco a partir do pescoço, membros superiores até os punhos e membros inferiores até os joelhos, com livre movimentação. O tecido do punho deve ser resistente ao esgarçamento mesmo após sucessivas lavagens.

O uniforme privativo deve atender todos os manequins dos usuários. O jaleco precisa cobrir todo o tronco, até o início do quadril. A sua manga, longa o suficiente para não expor as axilas (área de grande densidade de flora microbiana). A calça comprida precisa garantir cobertura completa da cintura e dos membros inferiores, protegendo o trabalhador contra contatos e também evitando a liberação da flora de suas pernas e períneo. AYLIFFE et $\mathrm{al}^{3}$ chegam até a sugerir calças com fechamento nos tornozelos como mais adequada para impedir a liberação dessa flora.

\section{2) Gorros}

Os cabelos soltos dispersam partículas carreadoras de bactérias, cuja maioria não são espécies patogênicas. Entretanto, S. aureus têm sido encontrados no cabelo de algumas pessoas do staff cirúrgico, mais freqüentemente naquelas que também os possuem no nariz. Embora ainda não comprovado por métodos moleculares apropriados, alguns estudos vêm demonstrando surtos de infecção de sítio cirúrgico por $\mathrm{S}$. aureus com cepas idênticas àquelas isoladas de profissionais 24 .

Embora as evidências científicas sobre a efetividade do gorro na prevenção de infecções sejam poucas, no mínimo, ele previne a queda de cabelo dentro da ferida. O C.D.C. dos EUA também concorda com o uso de cobertura no cabelo e na 
face. Para que tais objetivos sejam atendidos, há que se atentar para a "qualidade" dos gorros que são utilizados, seja no que se refere ao tipo de tecido, seja no design, permitindo cobertura total do cabelo. Gorros ditos "masculinos", com amarração abaixo da nuca e sem elástico, são os que mais freqüentemente deixam de fora grande quantidade de cabelo.

Embora não exista normatização para a confecção de gorros cirúrgicos, porém considerando sua necessidade de cobrir todo o couro cabeludo, consideraremos adequado aqueles com elásticos em toda a sua abertura, e suficientemente resistentes para cobrir todo os tipos de cabelos masculinos e femininos. Na composição do tecido, pode-se considerar adequado desde aqueles de tecido de algodão reprocessáveis até aqueles de "não tecido de uso único, porém com porosidade semelhante aos dos tecidos de uniforme privativos.

\section{3) Máscara cirúrgica ou protetor respiratório}

Do lado do cliente, a máscara justifica-se para evitar a liberação de microorganismos oriundos do nariz e da boca do profissional ao falar, tossir e respirar e, assim, protegê-lo de contaminação na incisão cirúrgica. Do lado do profissional, protege suas mucosas nasais e orais contra contato com secreções do paciente. Para isso, a máscara deve permitir cobertura completa do nariz, boca e regiões laterais e apresentar capacidade mínima de filtração por determinado período de tempo. Nesse aspecto, iniciam-se as dificuldades para determinar as suas características ideais de confecção sob condições específicas de sua utilização.

Ultimamente, vem se dando preferência a máscaras descartáveis. Contudo, algumas delas oferecem pouca proteção, dependendo do material com que são confeccionadas ${ }^{3}$. Do mesmo modo, aquelas de tecido de algodão podem aumentar ou diminuir a capacidade de filtração conforme a porosidade de suas fibras e o número de reprocessamentos ${ }^{17}$. A questão, portanto, não se situa em ser descartável ou reprocessável, mas na sua capacidade de retenção de microrganismos.

Sob condições laboratoriais, a pessoa normal expele muito poucas partículas quando em silêncio. Um espirro pode produzir 106 partículas e uma tosse, 5000 partículas. Nem todas as partículas contêm bactérias e nem todas irão se depositar numa incisão. Assim, uma máscara comum facilmente retém a maioria das partículas expelidas da boca e somente pequenas partículas estão aptas a escapar de áreas abertas ao redor do perímetro da máscara. Uma camada grossa de tecido de algodão ou de laminado pode assegurar a efetividade da máscara se forem bem desenhadas e com controles no seu reprocessamento ${ }^{24}$.
Pesquisa de $\mathrm{CHEN}^{6}$, com microorganismos semelhantes ao $M$. tuberculosis, mostrou que não existe grande diferença de capacidade de filtração entre máscaras com filtros HEPA e máscaras comuns descartáveis, tendo essas últimas, retido até $97,0 \%$ dos microorganismos.

Um estudo citado por ROY ${ }^{24}$ demonstrou que as máscaras não afetaram o número de bactérias depositadas em superficies de uma SO. O que fez uma grande diferença foi se a porta estava aberta ou fechada e se as pessoas estavam presentes. Outro estudo demonstrou que o não uso de máscara não afetou a incidência de infecção do sítio cirúrgico em cirurgias gerais. Entretanto, tal estudo nunca foi realizado em cirurgias limpas, onde poderia ser anti - ético submeter pacientes a tal experimento. A autora conclui que, devido a máscara auxiliar a reduzir a projeção de bactérias oriundas da conversação e da respiração, todos que entram na SO durante a cirurgia devem usar máscara que cubra totalmente a boca e o nariz.

Correntemente, têm sido consideradas adequadas, máscaras de algodão (com controle do tecido e do reprocessamento) e máscaras descartáveis sanfonadas de fibra de lã de camada dupla, com adaptadores maleáveis de metal ao nariz. Mesmo que tais máscaras consigam reter microorganismos oriundos da flora respiratória dos profissionais, a questão é sob quais situações, principalmente aquelas relacionadas ao tempo de uso ininterrupto e as condições bacteriológicas do seu usuário. LACERDA; GRAZIANO 17 referem que tais máscaras apresentam uma vida útil de 2 horas, findas as quais devem ser trocadas.

EARL $^{8}$ recomenda máscaras com capacidade de filtração de 95,0\% e com resistência a fluidos, as quais seriam suficientes para proteger das principais bactérias causadoras de infecção da ferida cirúrgica.

\section{4) Propé ou sapato privativo}

Justificado como barreira para prevenir a contaminação do chão de áreas críticas por microorganismos de áreas externas, que são carreados nas solas dos sapatos e podem ser liberados ao ambiente. Porém, sua eficácia no controle de infecções hospitalares tem sido questionada em vários estudos, cujo resumo de suas conclusões é apresentado a seguir

- ausência de diferença significativa de contaminação do chão com sapatos privativos, propés e calçados comuns;

- os propés "apanham" bactérias do chão e em seguida transferem-nas para outras áreas, uma vez que não é habitual a troca dos propés ao se mudar de SO, além de ser frequente o pisoteamento desapercebido ou indiferente sobre secreções orgânicas presentes no chão e sua disseminação por toda a área restrita e semi-restrita; 
microorganismos presentes no chão dificilmente se dissipam ao ar ambiente e não são aqueles causadores de infeção do sítio cirúrgico;

- o ato de caminhar é a mais importante causa da dispersão bacteriana do chão do que o tipo de cobertura de pés utilizado;

- a maior chance de contaminação de uma ferida cirúrgica com microorganismos oriundos do chão se dá antes pela sua veiculação e por contato do que pela sua disseminação do chão para o ar ambiente. Tal situação é demonstrada por CARTER $^{5}$, que observou que $79,0 \%$ do pessoal do seu estudo não lavava as mãos após a colocação e a retirada dos propés e detectou a presença dos mesmos microorganismos nas mãos e nas solas dos propés e dos sapatos.

Propés ou sapatos privativos continuam sendo recomendados pela OSHA (Occupational Safety and Health Administration) dos EUA para proteção do trabalhador contra contaminação com fluidos 8 . Entretanto, há que se atentar também para a sua eficácia como barreira, uma vez que os dispositivos atualmente utilizados (tamancos perfurados e propés) não evitam um ferimento dos pés com objeto pérfuro-cortante. Nesse caso, o ideal seria sapatos privativos fechados.

Contudo, a forma como tais dispositivos vêm sendo utilizados na prática não contribuem para o controle de infecções e determinam ainda, custos desnecessários. Vários outros estudos também discutem a eficiência dos propés como barreiras, de acordo com o tipo de tecido com que são confeccionados, concluindo que os de tecido sujam mais facilmente do que aqueles de plástico ou sapato privativo. Os de brim, desde que secos, são mais eficientes como barreira microbiológica do que a maioria dos descartáveis atualmente disponíveis, principalmente aqueles de malha, cuja porosidade permite passagem até de microrganismos multicelulares ${ }^{16}$

Diante de tais conclusões, somente consideraremos adequado sapatos privativos fechados ou aqueles de tecido de algodão e não tecido, desde que com reforço na sola. Aqueles de tecido, com controles de seu reprocessamento e os de tecido não - tecido descartáveis.

\section{5) Luvas cirúrgicas}

Originariamente, seu objetivo era estabelecer uma barreira impermeável para proteger o cliente da flora microbiana das mãos da equipe cirúrgica. Atualmente, também se reconhece sua importância contra riscos de infecção ocupacional pelo contato com sangue do cliente. As mãos são o principal instrumento na cirurgia e a parte do corpo que permanece maior período de tempo em contato direto com o sangue. Razões mais do que suficientes para sérias preocupações, que se iniciam pela qualidade da luva, no que se refere à flexibilidade, impermeabilidade e resistência ao tempo e aos movimentos cirúrgicos. Para tanto, devem ser de látex, esterilizadas e descartáveis. $O$ seu reprocessamento tem sido contra - indicado devido a dificuldade de controlar a manutenção de suas características originais, os riscos ocupacionais no seu reprocessamento e o custo-beneficio 3.

Mesmo as luvas de melhor qualidade $\mathrm{e}$ descartáveis não estão livres de sofrerem desgastes, furos e rasgos, que são diretamente dependentes do tempo e do tipo de cirurgia 26 . Uma alternativa é o uso de luvas duplas em cirurgias acima de 1 hora, cuja eficácia vem sendo comprovada e citada em vários estudos 13,19,21,25 Porém, há reclamações de diminuição da sensibilidade tátil e de "aperto das mãos em demasia. Outra alternativa tem sido a recomendação de troca das luvas a cada 2 horas de cirurgia, além de observação frequente das mesmas3. Mais recentemente, alguns fabricantes vêm desenvolvendo luvas mais resistentes para procedimentos que exigem maior pressão e força física, como ortopedia.

Mesmo assim, a densidade da luva ou a luva dupla dificilmente irão evitar injúrias com objetos pérfuro-cortantes. Na verdade, a melhor forma de proteção ocupacional se encontra na técnica cirúrgica, seja pela perícia de quem a executa, seja pelo desenvolvimento de novos instrumentos que protejam mais as mãos.

Importância também . dever ser dada à apresentação das luvas, em pares, várias numerações e acondicionadas de forma que permitam a abertura do pacote e sua colocação com técnica asséptica. Seu uso adequado também deve ser garantido pela presença de punhos reforçados, que permitam boa adaptação ao punho do avental.

\section{6) Protetor ocular}

Recomendado para proteção ocupacional, evitando contato direto da mucosa ocular com sangue e outros fluidos do cliente. Entretanto, seu uso tem encontrado resistência, pela diminuição da acuidade visual e embaçamento por escape da respiração da máscara para dentro do visor.

A escolha de protetores inclui viseiras bem amplas de acrílico ou vidro e protetores da face contra fluidos ${ }^{9}$. Porém, como seu uso está dependente principalmente da conscientização do profissional, avaliaremos neste estudo como adequado, os hospitais que fornecem esse dispositivo com modelo de visão amplo e aderente às pele circunvizinha, a fim de não provocar o efeito embaçante. 


\section{RESULTADOS E DISCUSSÃO}

Os componentes da paramentação cirúrgica utilizados nos hospitais deste estudo foram avaliados de acordo com critérios previamente estabelecidos (anexo 2). Os resultados obtidos são apresentados, conforme segue:

Tabela - Avaliação das especificações técnicas dos componentes da paramentação cirúrgica utilizados nos centros cirúrgicos de hospitais do município de São Paulo. São Paulo, 1998.

\section{1 - Especificações técnicas dos componentes da paramentação cirúrgica}

Tais avaliações referem-se ao tipo de tecido, modelo, tamanho e fornecimento pelos hospitais, tendo sido agrupados na tabela abaixo.

\section{\begin{tabular}{l}
$\begin{array}{l}\text { Componente } \\
\text { Avaliação }\end{array}$ \\
\hline
\end{tabular}}

\begin{tabular}{lccccccccccccccc}
\hline ADEQUADO & 02 & 14,3 & 0 & 0,0 & 13 & 92,9 & 01 & 7,1 & 12 & 85,8 & 01 & 7,1 & 14 & 100,0 \\
PARC. ADEQ. & 04 & 28,6 & 14 & 100,0 & 0 & 0,0 & 13 & 92,9 & 0 & 0,0 & 12 & 85,8 & 0 & 0,0 \\
INADEQ. & 08 & 57,1 & 0 & 0,0 & 01 & 7,1 & 0 & 0,0 & 2 & 14,2 & 01 & 7,1 & 0 & 0,0 \\
\hline TOTAL & 14 & 100,0 & 14 & 100,0 & 14 & 100,0 & 14 & 100,0 & 14 & 100,0 & 14 & 100,0 & 14 & 100,0 \\
\hline
\end{tabular}

Conforme são mostrados nos dados obtidos, as luvas foram avaliadas como adequadas em todos os hospitais, pois todos as forneciam em quantidade suficiente, com variações de tamanho $(6,0$ a 8,0$)$, descartáveis, embalagem exclusiva para cada par, que permitem sua abertura e colocação com técnica asséptica. Alguns hospitais também possuíam luvas anti - alérgicas, com textura mais resistente para cirurgias ortopédicas e com textura mais fina (ultraderme) para procedimentos mais delicados.

Os protetores oculares estavam adequados em $13(92,9 \%)$ hospitais, por serem fornecidos aos profissionais e com modelo permitindo a aderência ao redor da mucosa ocular. Não foi possivel avaliar sua capacidade anti - embaçante, uma vez que, conforme verificado na parte I deste estudo, os profissionais não os estavam utilizando.

A maioria dos hospitais $(85,8 \%)$ também fornecia máscaras cirúrgicas consideradas adequadas, por serem de tecido não-tecido, camada dupla, sanfonada, com adaptador maleável de nariz e descartáveis. Dois hospitais possuíam máscaras com camada tripla. As avaliações consideradas inadequadas deveram-se ao fato dos hospitais fornecerem máscaras de algodão, porém, conforme se verá no item a seguir, sem controle adequado no seu reprocessamento.

Todos os uniformes privativos de centro cirúrgico dos hospitais estudados foram avaliados como parcialmente adequados. A não adequação total deveu-se aos tamanhos e modelos: jalecos e calças curtas, não permitindo cobertura completa das regiões a eles destinados; ausência de fechamento nos tornozelos (exceto 2 hospitais), mangas curtas, não protegendo as axilas (exceto 1 hospital). Todos eram de algodão. Contudo, conforme entrevistas apresentadas abaixo, o controle de reprocessamento não era adequado.

Semelhante aos uniformes privativos, os aventais cirúrgicos da maioria dos hospitais foram avaliados como parcialmente adequados $(85,8 \%)$. Com apenas uma exceção, em todos os hospitais, os aventais eram de tecido de algodão, possuindo punhos bem adaptados e OPAS. A razão da não total adequação foi por não possuírem variação de tamanhos que permitissem a cobertura completa do tronco e pernas até os joelhos. Além disso e, semelhante aos outros componentes de tecido de algodão, o seu reprocessamento não era adequado na maioria dos hospitais. Apenas 1 hospital foi avaliado como adequado, possuindo aventais de tecido de algodão e de não - tecido reforçado, dentro dos critérios previamente estabelecidos. O hospital avaliado como inadequado, deveu-se à ausência de OPAS.

A grande maioria dos gorros foram avaliados como parcialmente adequados, sendo de tecido não - tecido descartável em 13 hospitais e de algodão em 2 hospitais. A sua não total adequação deveu-se aos gorros ditos "masculinos" , com amarração posterior, que nem sempre permite cobertura dos cabelos mais longos. Em outras situações, as toucas com elástico não eram suficientemente resistentes, possibilitando seu deslocamento ou não sustentando todos os tipos de cabelos, 
Os propés foram os componentes que alcançaram maior índice de inadequação $(57,1 \%)$, pois não tinham reforço na sola, sem variação de tamanho, de tecido de vários tipos: malha fina, algodão cru, brim e não - tecido. Observou-se, inclusive, que alguns eram usados com rasgos e furos. Somente 2 hospitais possuíam sapatos privativos utilizados por alguns profissionais.

\section{2 - Aquisição e controle do reprocessamento da paramentação cirúrgica.}

As informações foram obtidas através de entrevistas com enfermeiros de centro cirúrgico e de centro de material dos hospitais estudados. Os critérios de aquisição dos componentes utilizados na maioria dos hospitais eram basicamente testes na instituição (colocar em uso e aguardar as respostas), custo - beneficio e algumas vezes, somente o custo.

Com relação ao controle do reprocessamento, todos os hospitais possuiam algumas medidas, realizadas pela lavanderia e pelo centro de material. Contudo, o controles tratavam-se eminentemente de "teste visual" das condições das roupas (sujidade, rasgos, etc.). Alguns hospitais também acrescentavam testes de permeabilidade e controle de cerzimento. Três hospitais reprocessavam propés originalmente de uso único (descartável).

Os enfermeiros reconheceram, durante as entrevistas, a falta de controle de qualidade efetiva no reprocessamento, não sendo possivel determinar a meia vida dos tecidos, onde muitas vezes os componentes são utilizados até rasgar e mesmo rasgados. Há dificuldade na reposição das roupas enviadas para a lavanderia, que demoram para retornar. Referiram também a baixa qualidade de resistência dos tecidos.

\section{CONCLUSÃO E CONSIDERAÇÕES FINAIS}

Conforme visto na parte I desse estudo, a paramentação cirúrgica é amplamente reconhecida como necessária para a prevenção de riscos biológicos em cirurgia. Baseando em literatura científica pertinente, a parte II desse estudo buscou estabelecer critérios mínimos para avaliação de qualidade dos seus componentes. A maior dificuldade nesse empreendimento referiu-se à qualificação dos tecidos de confecção como barreira de proteção contra passagem de microrganismos e contato com sangue e outros fluidos, uma vez que a própria literatura científica disponivel não apresenta estudos conclusivos e consensos. Os outros critérios puderam ser estabelecidos com relativa objetividade: design, tamanho, embalagens, seleção na aquisição e controle do reprocessamento. Portanto, os critérios de avaliação previamente estabelecidos foram válidos, pois permitiram reconhecer aspectos positivos e problemáticos.

Observou-se que existem semelhanças nos componentes da paramentação da maioria dos hospitais deste estudo, no que se refere ao design e tipo de tecido.

A tendência de gorros e máscaras é o material tecido não - tecido, descartável, em substituição ao tecido de algodão. Porém, não está garantida a qualidade dos gorros, pois nem todos apresentaram estruturas reforçadas que garantem cobertura total e sustentação dos cabelos.

Os aventais e uniformes privativos são predominantemente de tecido de algodão e com OPAS, porém não apresentam todas as variações de tamanho necessárias aos diferentes usuários, que permitam a total cobertura das regiões corporais a eles destinadas. Somente um hospital possuía calça privativa com fechamento nos tornozelos e manga de jaleco que cobria a axila.

O componente mais adequado foi a luva e o maior indice de inadequação foi o propé, principalmente no que se refere à eficácia de seu tecido como barreira.

O aspecto mais problemático, conforme visto, situa-se na ausência ou insuficiência de controle de reprocessamento dos componentes re - utilizáveis.

Por conclusão, na qualificação da paramentação cirúrgica, a principal questão não se encontra em decidir se ela deve ser confeccionada com tecidos de algodão ou tecido - não tecido, totalmente impermeáveis, descartáveis ou reprocessáveis. A questão se encontra principalmente na sua eficácia como barreira de proteção, o que significa estabelecer padrões mínimos de sua porosidade, design, tamanhos variados que permitam a cobertura completa das regiões corporais e controle efetivo da aquisição e do reprocessamento daqueles re-utilizáveis.

\section{REFERÊNCIAS BIBLIOGRÁFICAS}

1.ASSOCIATION OF OPERATION ROOM NURSING. Proposed recommended practices for uses and selection of barrier materials for surgical gowns and dropes. AORN J. , v.62, n.3, p.449-53, 1995.

2. AYLIFFE, G.A.A; LILLY, H. Cross-infection and its prevention. J.Hosp.Infect., n.6, p.47-57, 1985. Suppl. B.

3. AYLIFFE, G.A. et al. Control of hospital infection. London, Chapman \& Hall Medical. 1992. p. 211-30. Cap. 11. Asepsis in operating theatres. 
4. BELL, D.M. et al. Preventing bloodborne pathogen transmission from healthcare worker to patients. Surg. Clin.North Am., v.75, n.5, p.1189-203, 1995.

5. CARTER, R. Ritual and risk. Nurs.Times, v.86, n.13, p.63-4, 1990.

6. CHEN, S.K. et al. Evaluation of single-use masks and respirators for protection of health care workers against mycobacterial aerosols. Am.J.Infec.Control., v.22, n.2, p.65$74,1994$.

7. COOP, G. et al. Footwear practices and operating room contamination. Nurs.Res., v.36, n.6, p.366-9, 1987.

8. EARL, A. Operating room. In: Olmsted NR (ed). Infection control and applied epidemiology. St. Louis, Mosby, 1996. Cap. 95 , p.95 - 7.

9. FRY, D.B. et al. Prevention of blood exposure. Surg.Clin.North Am., v. 75, n.6, p. 1141-57, 1995.

10. GARNER, J.S. CDC Guideline for prevention of surgical wound infections. Today's OR Nurse, v.8, n.3, p.33-40, 1986.

11. GARNER, J.S. Guideline for isolation precautions in hospitals. Inf.Cont.Hosp.Epidem., v.17, n.1, p.50-80, 1996.

12. GAYA, H. Is it necessary for staff and visitors in an intensive care unit to wear masks, hats, gowns and overshoes? Nurs.

Times, v. 86, n.13, p.63-4, 1990.

13. GERBERDING, J.L. Procedure-specific infection control for preventing intraoperative blood exposures. Am.J.Infec.Control., v.21, n.6, p.364-'7, 1993.

14. GERBERDING, J.L. et al. Are universal precautions realistic? Surg.Clin.North Am., v.75, n.6, p.1091-103, 1995.

15. GOUVEIA, V.R. Embalagens para esterilização: tecidos e não tecidos. Rev. SOBECC, v.2, n.4, p. 10-3, 1997.

16. GRAZIANO, K.U. et al. Uso de propés no controle da contaminação do piso da sala de operação. In: CONGRESSO BRASILEIRO DE ENFERMAGEM, 43., Curitiba, 1991. Programa. ABEn, 1991, p.158.
17. GRAZIANO, K.U.; LACERDA, R.A. Paramentação cirúrgica. In: LACERDA, R.A. et al. Buscando compreender a infecção hospitalar no paciente cirúrgico. São Paulo, Atheneu, 1993. p.48-52.

18. LEWIS Jr., R.F. et al. Epidemiology of injuries by needles and other sharp instruments. Surg.Clin.North Am., v.75, n.6, p.1105-21, 1995.

19. LYNCH, P.; WHITE, M.C. Perioperative blood contact and exposures: a comparision of incident reports and focused studies. Am.J.Infec.Control., v. 21, n.6, p.357-63, 1993.

20. McCULLOUGH, E.A. Methods for determining the barrier efficacy of surgical gowns. Am.J.Infec.Control., v. 21, n.6, p.368-73, 1993

21. NICHOLS, R.L. The operating room. In: BENNETT, J.V.; BRACHMAN, P.S. (ed.) Hospital infections. Boston, Little Brown, p. 461-73, 1992.

22. RITTER, M.A.; MARMION, P. The exogenous sources and controls of microrganisms in the operating room. Orthop. Nurs., v.7, n.4., p.23-8, 1988.

23. RODRIGUES, E. Reutilização de campos duplos de algodão para embalagem de artigos médico-hospitalares na esterilização por calor úmido. São Paulo, 1998. Projeto de pesquisa apresentado para exame de qualificação de doutorado do programa de pós - graduação da Escola de Enfermagem da USP. /mimeografado/.

24. ROY, M.C. The operating theater: special environnental area. In: Wenzel , R.P. Hospital infection. Baltimore, 1997 , cap.26.

25. TELFORD, G.L.; QUEBBEMAN, E.J. Assessing the risk of blood exposure in the operating room. Am. J. Infec. Control., v.21, n.6, p.331-6, 1993.

26. ZINNER, N.L. How safe are your gloves? A study of protective barrier properties of gloves. AORN J., v.59, n.4, p.876-82, 1994. 


\section{ANEXO 1: Instrumento de coleta de dados dos componentes da paramentação cirúrgica}

Parte A: Caracterização dos hospitais do estudo

-Tipo de assistência: ( ) privados ( ) públicos

- Capacidade de leitos: ( ) médio porte () grande porte ( ) capacidade extra

- Volume médio mensal de cirurgias

Parte B: Especificações técnicas dos componentes

I - Propé

- Tipo de tecido:

Descrição do modelo:

Avaliação:

- tamanho:

- Critérios de seleção de aquisição e de reprocessamento (se for o caso):

II - Uniforme privativo

- Tipo de tecido:

- Descrição do modelo:

- Tamanho:

Avaliação:

- Critérios de seleção de aquisição e de reprocessamento (se for o caso):

III - Protetor ocular:

Tipo de tecido:

- Descrição do modelo:

- Oferecido pelo hospital: ( ) sim ( ) não

Avaliação:

Gorro:

- Tipo de tecido:

- Descrição do modelo

- Tamanho:

Avaliação:

- Critérios de seleção de aquisição e de reprocessamento (se for o caso):

Máscara cirúrgica:

- Tipo de tecido:

- Descrição do modelo:

- Máscaras de uso único: ( ) descartáveis

- Critérios de seleção de aquisição e de reprocessamento (se for o caso):

Avental cirúrgico:

- Tipo de tecido:

- Descrição do modelo

- Critérios de uso

- Critérios de seleção de aquisição e reprocessamento (se for o caso):

Avaliação:

Luvas cirúrgicas:

- Tipo de tecido e modelo:

- Descartáveis: ( ) sim ( ) não

- Tamanhos:

Avaliação: 
ANEXO 2: Critérios de avaliação das especificações técnicas dos componentes da paramentação cirúrgica

\section{II - UNIFORME PRIVATIVO \\ Adequado}

- calça comprida e jaleco de algodão ou não-tecido reforçado. Tamanhos variados, que permitem a cobertura completa do tronco, pernas e axilas de todos os usuários. Calça com fechamento no tornozelo.

\section{Parcialmente adequado}

- calça comprida e jaleco de algodão ou não-tecido reforçados. Porém :

a) não apresenta tamanhos variados que permitam a cobertura completa do tronco e/ou pernas e/ou axilas de todos os profissionais; ou:

b) não possui punhos nos tornozelos.

\section{Inadequado}

- calça comprida e jaleco de algodão ou não-tecido reforçado. Porém, não atende simultaneamente os critérios a) e b) acima citados.

\section{III- PROTETOR OCULAR}

\section{Adequado}

- fornecido pelo hospital. O modelo é anti-embaçante e permite oclusão e proteção completa da mucosa ocular.

\section{Parcialmente adequado}

- fornecido pelo hospital, porém o modelo não é adequado (embaçante e/ou não permite a oclusão e proteção completa da mucosa ocular).

\section{Inadequado}

- hospital não fornece protetores para todos os profissionais da equipe cirúrgica.

\section{IV- GORRO}

\section{Adequado}

- tecido de algodão ou não-tecido maleáveis. Tamanho e modelo (com estruturas reforçadas) que permitem tanto a cobertura completa de qualquer tipo de cabelo de ambos os sexos quanto a sua manutenção durante toda a permanência no local. Aqueles de uso único não são reprocessados.

\section{Parcialmente adequado}

- tecido de algodão ou não-tecido maleáveis. Aqueles de uso único não são reprocessados. Porém :

a) os modelos não apresentam tamanhos e estruturas reforçadas, não permitindo a cobertura completa de qualquer tipo de cabelo de ambos os sexos; ou:

c) há modelos diferentes, sendo que alguns atendem todos os critérios de adequação e outros não.

\section{Inadequado}

- tecido de algodão ou não tecido maleáveis. Porém :

a) os modelos não apresentam tamanho e estrutura reforçada, não cobrindo completamente todos os tipos de cabelos de ambos os sexos e:

b) aqueles originalmente de uso único são reprocessados.

\section{V- MÁSCARA}

\section{Adequado}

- tecido não-tecido. Sanfonadas. Camada dupla. Adaptador maleável de nariz. Permite vedação completa do nariz, boca e laterais. Originalmente de uso único e não são reprocessadas.

-tecido de algodão. Permite vedação completa do nariz, boca e laterais.

\section{Parcialmente adequado}

- tecido não-tecido. Originalmente de uso único e não são reprocessadas. Porém não atende a um dos seguintes requisitos: camada dupla ou adaptador maleável de nariz ou sanfonada.

\section{Inadequado}

- tecido não-tecido, que não atendem a dois ou mais dos seguintes requisitos: camada dupla, adaptador maleável de nariz e sanfonada e/ou:

- São reprocessadas. 


\section{VI - AVENTAL CIRÚRGICO}

\section{Adequado}

- tecido de algodão ou tecido não-tecido reforçado. Com OPAS e punho. Apresentam tamanhos variados, que permitem a cobertura completa dos braços até os punhos, tronco e pernas até os joelhos de todos os profissionais. Possuem amarração interna e externa. Aqueles de uso único não são reprocessados.

\section{Parcialmente adequado}

- tecido de algodão ou não-tecido reforçado. Com OPAS e punhos. Aqueles de uso único não são reprocessados. Porém

a) não apresentam tamanhos variados que permitam a cobertura completa do tronco, braços até os punhos e pernas até os joelhos de todos os profissionais; ou:

b) não apresentam amarração interna e externa; ou:

a) há os dois tipos de aventais (algodão ou não tecido), sendo somente um deles totalmente adequado.

\section{Inadequado}

a) Aventais de uso único que são reprocessados; e/ou:

b) Aventais sem OPAS ou punhos, qualquer que seja o tipo de tecido .

\section{VII- LUVAS CIRÚRGICAS}

\section{Adequado}

- descartáveis, de uso único, de látex, esterilizadas. Numeração que atende variações anatômicas de todos os profissionais. Punhos permitem boa aderência sobre o punho do avental. Embalagem exclusiva para cada par, luvas que permite sua abertura com técnica asséptica. Não são reprocessadas.

\section{Parcialmente adequado}

- descartáveis, de uso único, de látex, esterilizadas e não são reprocessadas. Punhos das luvas permitem aderência sobre os punhos do avental. Embalagens exclusivas para cada par de luvas que permita sua abertura com técnica asséptica. Porém não há numeração variada que atenda as variações anatômicas de todos os profissionais.

\section{Inadequado}

- não atende a dois ou mais dos requisitos de adequação. 